\title{
Water insecurity, illness and other factors of everyday life: A case study from Choma District, Southern Province, Zambia
}

\author{
Richard A Marcantonio ${ }^{1 *}$ \\ Anthropology Department and Joan B Kroc Institute for International Peace Studies, University of Notre Dame, Hesburgh Center, \\ Notre Dame, IN 46556, USA
}

\begin{abstract}
Recent reports from the UN find that 2.6 billion people have gained access to improved drinking water sources since 1990, but 663 million people still live without. Other recent work demonstrates that 4 billion people annually face severe water scarcity as a result of seasonal fluctuations in water availability and quality. How is it that, despite the significant development in water resource availability documented by the UN, literally billions of people are regularly experiencing water insecurity? To begin to understand how a lack of access to reliable water resources affects everyday life, I focus on a specific outcome of water insecurity: waterborne illness. Given the difficulty in linking illness to a particular source, this research focuses on perceptions of water safety. I ask participants about illness they perceive coming from their drinking water, conducting faceto-face surveys $(N=224)$ spatially distributed around Choma town, Southern Province, Zambia. In particular, I investigate how these perceptions affect everyday life and what intersecting factors are likely to increase or decrease the probability of a person perceiving drinking water as the source of their illness. Our findings demonstrate that individual perceptions of waterborne illness are tightly coupled with perceptions of water needs being met or not, water flexibility (water storage capacity and water resource type and number available), total water use, food security and distance to various services. My work identifies and qualifies intersecting relationships that are critical to the design of any policy or other means of intervention intended to reduce experienced and perceived waterborne illness and other everyday needs of subsistence farmers facing the challenges presented by climate change and other forms of environmental change.
\end{abstract}

Keywords: water, illness, perceptions, insecurity, environmental change

\section{INTRODUCTION}

United Nations Sustainable Development Goal 6 states that 'clean, accessible water for all is an essential part of the world we want to live in' and that access to clean water is a fundamental human right (UN, 2010, 2016a). Recent reports from the UN find that 2.6 billion people have gained access to improved drinking water sources since 1990, but 663 million people are still without (UN, 2016a, 2016b). Other studies estimate that, in fact, 844 million people are without access to an improved water source (WHO, 2017a). Further, a recent study by Mekonnen and Hoekstra (2016) tells a similar story: 4 billion people annually face severe water scarcity as a result of seasonal fluctuations in water availability. Part and parcel to water insecurity is waterborne illness, which, despite massive development efforts to improve water resource access, is still a leading cause of disease and death in developing countries (UNICEF, 2009, 2015). How is it that, despite the significant development in water resource availability documented by the $\mathrm{UN}$, literally billions of people are regularly engaging with water scarcity and waterborne illness? Here I address this question using household-level survey data of smallholder farmers in Choma District, Southern Province, Zambia, with specific emphasis given to investigating perceptions of waterborne illness - for example, whether a person believes they have become ill, or not, from the water they drink and their experience of being ill - and its concomitant correlates.

Waterborne illnesses poses a substantial threat to human health and development (WHO, 2017a), a threat that is

\footnotetext{
To whom all correspondence should be addressed
}

e-mail:rmarcant@nd.edu

Received 4 July 2017; accepted in revised from 25 September 2018 expected to continue to increase as a result of global climate change (Adger, 2010; Confalonieri et al., 2007; Edenhofer et al., 2014; Pachauri et al., 2014). The impacts of waterborne illness increase the economic and intra- and interpersonal stress burdens experienced by affected families via increased rates of morbidity and mortality, particularly among children under the age of 5 and elderly populations (Günther and Fink, 2010; Waite et al., 2016). Although substantive progress in water access and development in recent years has reduced the risk of waterborne illness globally, it is still a leading source of disease in developing countries (UNICEF, 2015; WHO, 2016; WSP, 2016). Diarrhoea, a common sign of waterborne illness, is the second leading cause of death for children under the age of 5 years, killing approximately 760 000 children annually (WHO, 2016). Waterborne illness is prolific on the African continent; until 2015, diarrhoea was responsible for $7.7 \%$ of all deaths (annually) (WHO, 2016). Identifying incidence of waterborne illness can be difficult, especially when the symptoms of illness have become so normalized in everyday life that people may not perceive or recognize that they have contracted a waterborne illness (Murphy et al., 2017). To begin to combat waterborne illness it is critically important to identify where it is happening, how and when people perceive they have experienced illness from water, and what correlated indicators coexist and interact with it, i.e., what factors promote or reduce the risk and incidence of those experiencing illness such as water resource access (Dangour et al., 2013; Fewtrell et al., 2005). To accomplish this requires locally relevant and produced data. This investigation uses household-level data to understand the place and circumstances in which waterborne illness is occurring in Choma District, Southern Province, Zambia. 
Household water resources can generally be divided into two categories: 'improved' water sources; and 'unimproved' water sources (WHO, 2017b); here I follow suit. Improved water sources include water piped into the home and boreholes, but other types of improved sources exist (Pullan et al., 2014). Unimproved water sources include surface water sources (rivers, streams, ponds, etc.), unprotected wells and pooled natural springs. These sources are often unprotected and exposed to contaminants (animal faeces, dust, etc.), and water treatment mechanisms are often not available at collection points (UNICEF, 2009; WSP, 2012). The result is an increased risk of waterborne illness due to the potential for varying amounts of contaminants (Morris et al., 2012; Sobsey, 2002). For example, Prüss-Ustün et al. (2014) find that deaths resulting from diarrhoea more often result from drinking from unimproved water resources than improved water sources. Similarly, Pullan et al. (2014) estimate that unimproved drinking-water sources and sanitation are responsible for $85 \%$ of deaths from diarrhoea and $1 \%$ of the global burden of disease. In contrast, water provided by improved water sources is also considered of higher quality than water from unimproved water resources because it may have been treated through a municipal water system (for piped water systems) or because it is drawn directly from groundwater stores (boreholes) (Abramson et al., 2013; Pullan et al., 2014; Sobsey, 2002). Recognizing the disparity in quality between these two water source types (improved vs. unimproved), I differentiate them in my statistical analyses in a novel way, exhibiting a new approach to investigating the relationship between water access and waterborne illness. By interacting a water resource type variable with an estimated water use variable, I control for both the type of water resources a household has access to and how much water they use or consume from that resource, finely parsing out the relationship between a participant and a resource type, and the impacts this relationship has on perceptions of waterborne illness. The results demonstrate that participants' perceptions of waterborne illness are significantly influenced by whether they have access to an improved water resource or not and, importantly, how much water they consume from an improved source vs. an unimproved water source.

In this paper I first work to fully describe the study area and the data collection process conducted through field work. Next, I thoroughly review each independent variable used in our statistical model and relate them to relevant literature and their contextual origins, i.e., I explain what each variable represents of and within local level contexts. Then I present a statistical model to demonstrate what independent variables are correlated to participants experiencing waterborne illness, when accounting for the other potential factors. Finally, I will interpret these variables by pairing them with their local-level contexts to understand what they mean in local terms and circumstances. By situating the data in the contexts from which they are derived, I work to build a highresolution and locally relevant account of waterborne illness that can effectively inform water resource development at local, regional, and global levels of implementation. This study fills a critical gap in household-level understandings of water scarcity and access in Southern Province, Zambia, as it is the first academic study to take this approach in this specific location, despite water issues being historically prolific in the area (Chisanga and Hamazakaza, 2008). This study complements and contributes to the extensive body of research on testing and validating a scalable and culturally relevant measure of water scarcity and water resource access (Hadley and Freeman, 2016; Hadley and Wutich, 2009; Jepson et al., 2017; Stevenson et al., 2012; Wutich and Brewis, 2014)yet a relative paucity of tools to assess the occurrence and severity of water insecurity at the household level. We sought to assess the validity and reliability of a household water insecurity scale in a rural Ethiopian context. Secondary data on water insecurity from up to 1934 rural Ethiopian households that had participated in a water and sanitation intervention was analysed. Exploratory factor analysis and Cronbach's alpha were used to assess dimensionality of the water insecurity responses and parametric and non-parametric tests used to test for differences in household water insecurity scores across household types and objective measures of household water access. Factor analysis revealed one dominant factor and the Cronbach's alpha of the water insecurity scale was 0.94 . Households with access to improved water sources, that lived close to water collection points, that did not farm, and that felt they had "enough" water all scored as significantly more water secure on the household water insecurity scale $(\mathrm{P}<0.05$ by focusing specifically on the relationship between perceptions of illness and water resource access, and by demonstrating a novel way of controlling for the effect of water resource use on this relationship by interacting resource type and water drawn from that resource.

\section{Study area}

Zambia is a land-locked developing country in Sub-Saharan Africa that has experienced increased variation in annual and intra-annual rainfall over the past few decades (Chisanga and Hamazakaza, 2008; Stern and Cooper, 2011). Climate models generally suggest these impacts will continue in southern Africa and will likely increase for at least the next few decades (Edenhofer et al., 2014; Pachauri et al., 2014). Within Zambia, the most water-scarce region is the Southern Province (Chisanga and Hamazakaza, 2008). Fluctuations in inter-annual and intra-annual precipitation have the potential to disrupt the development of this primarily agrarian-based state (Mtambanengwe et al., 2012; Tschakert, 2007). All Zambians are affected by these impacts; however, those closer to urban centres may be less directly impacted by the changing climate due to increased access to health services and piped water, and their general participation in nonagriculture-based primary employment.

In 2010, diarrhoea was the second leading disease resulting in death in Zambia for children under 5 years old (Murray and Lopez, 2013). According to the Water and Sanitation Program (2012), nearly $90 \%$ of diarrhoea cases were caused by poor water conditions. The percentage of the population with access to improved water sources in Zambia was $74 \%$ in 2015, which was much lower than global average level, 91\% (WHO, 2016). Although access to improved water sources in rural areas increased from $46 \%$ (2010) to $51 \%$ (2015); it was still lower than global rural average level, 84\% (UNICEF, 2015).

None of our participants had access to piped water, which is representative of the overwhelming majority of people in the rural areas of Choma District. Many participants made mention of the fact that piped water does not exist in the rural areas, and that only urban dwellers had it. Due to the lack of piped water access, water for household consumption, watering livestock, garden crop production, and other daily water needs has to be fetched from surface water and/or groundwater resources. Surface water resources in this area include ponds, 
lakes (formed by dammed streams), ephemeral streams, and open-top wells. Inter-seasonal variation in precipitation and evapotranspiration rates affects the quality and quantity of these resources (Chisanga and Hamazakaza, 2008; Delpla et al., 2009; Mekonnen and Hoekstra, 2016; Stringer et al., 2009). During the dry season, many of these sources dry-up leading to increased competition between (i) human-to-human demand and (ii) human-to-livestock demand. The combination of increased livestock usage (leading to increased incidence of faecal coliform and other pathogen contamination from animals defaecating in or nearby the water resource) and impacts associated with dry-season conditions (increased water temperature which increases water pathogen rates, increased airborne dust that deposits in the water resource, etc.) can result in significant negative health impacts and further degrade individual and household well-being. Participants in the study directly noted these interactions in their responses. For example, Mrs. Mulamfu, a 42-year-old mother of 6, said, "Every few days during the dry season I have to repair the fence around my dambo. Either kids or cattle break-in to get water, leaving it dirty. I am happy to share water if the kids ask, I just want to keep the animals out and the area clean. I have to drink from it, too!"

The most prominent groundwater resource in the context of Southern Zambia is the borehole. A borehole is a vertically drilled shaft in the ground with a pipe inserted that water travels up by the creation of negative pressure, most often generated through a hand-pump mechanism. The water extracted at these points is often pathogen-free since it has been naturally filtered through porous soil and rock as it percolated from the surface down into the water table. However, while usually (and often correctly) associated with higher quality and quantity of water, boreholes are not without their fault: First, depending if the pipe inserted is made of metal or PVC, there is the potential for it to rust and lead to metal particulates in the water produced. Second, depending on fluctuations in the water table and the depth to which the borehole is dug, there is the potential for it to go dry. After several dry seasons or if there is significant extraction that exceeds the natural replenishment rate (i.e. the maximum sustainable water yield threshold is exceeded resulting in a net negative) the water table may drop to a depth below a given well; both of these phenomena have occurred in Southern, Zambia, where compounding interseasonal droughts and commercial farming water extraction rates (surface and ground) have been increasing (Chisanga and Hamazakaza, 2008).

\section{MATERIALS AND METHOD}

I rely on extensive, face-to-face structured surveys $(N=224)$ and unstructured interviews $(N=28)$ to capture rich qualitative and quantitative information to contextually ground findings related to water scarcity, perceptions of illness related to water, and adaptive capacities to water issues.

\section{Survey}

The survey included questions on socio-demographic information such as age and the number of years the participant has been a farmer; open-ended questions ranging from the participant's definitions of conflict to sources of general worries; to closed-ended questions about crop water needs and changes in rainfall patterns. The survey was pretested in the field $(n=21)$ to ensure the reliability of each survey question and enumerator training. The predominant language spoken in Choma district is Tonga (CSO, 2010). Specific Tongan words were tested in an effort to remove bias from the way the questions were asked. For example, kuliblika (worries) was selected after multiple trials and discussions to make sure that it did not specify a type or form of worry that would be associated with water issues. To quantify the qualitative responses from participants, a two-person independent coder method was employed. To test interrater reliability, Cohen's Kappa analysis was used $(k=0.89)$.

The survey questions were organized as follows:

- Socio-demographic questions focusing on age, gender, education, household size, etc.

- Questions asking about water storage and sharing, sources of water, and fetching water

- Questions asking about water needs, specifically focusing on household, crop, and cattle water needs

- Questions on perceptions of rainfall trends, capturing temporal variations, focusing on the past 10 years, last year, and next year

\section{Sampling strategy}

My sampling strategy was purposive, using locally developed administrative boundaries as a guide to spatially distribute our sample. The key unit used in sampling was the agricultural camp which are administrative units defined by the Zambia Ministry of Agriculture (camps hereafter). There are 32 camps within Choma District, within which 47714 small-scale farmer households live (DACO, 2015). Camps are led and monitored by a camp officer and a community agricultural committee (FAO, 2009). Through these entities smallholder farmers are able to convey their farming needs, ranging from farming subsidies to technical assistance, to the government. Seven camps were sampled in total, dispersed around Choma town to cover each cardinal direction. The local Zambian Agricultural Research Institute (ZARI) at Mochipapa Station introduced our research team to each camp officer for every camp sampled. The camp officer would then introduce the research team to individual farmers within the camp. Data were collected in the field using two local enumerators fluent in the predominant local language (Tonga).

Camps are divided into 8 zones each. Zones are drawn based on local-level contexts such as villages within the camp, spatial layout, and traditional governance structures (DACO, 2015). Zone boundaries do not divide the area equally along a precise line; however, they do provide coverage of the entire camp and capture important variations therein. We sampled each of the 8 zones within each target camp. In each zone we interviewed 4 participants, resulting in 32 participants sampled per camp, and 224 participants sampled in total $(N=224)$. Participants within each zone were chosen using the following rules for selection: that participants were not contacted prior to our arrival at their household; that they would be surveyed at their residence; and that they would not be neighbours. These rules ensured dispersed sampling within each zone and helped mitigate some selection bias. Data collection occurred in the months of June, July and August of 2015.

Unstructured interviews $(N=28)$ were conducted with civil servants and other government representatives and local, non-government leadership figures, ad hoc, when chance encounters made these opportunities available. The information from these interviews further contextualizes the data from the structured surveys. 


\section{Participant characteristics}

In total, 224 households were surveyed, across an area of approximately $4000 \mathrm{~km}^{2}$ (see Fig. 3). Of these, $59.8 \%$ of participants were male, and average age was 48.3 years $(\mathrm{SD}=$ 15.5 years). Education levels varied from no formal education to college graduate with a standard deviation of 3.4 grades and an average level of Grade $7-8$ being completed. The average distance a participant lived from a government-funded clinic was $14.7 \mathrm{~km}$. The main water sources participants reported having access to were ponds (70.1\%), communal boreholes (67.4\%), and rivers or streams (46.0\%) (see Fig. 1). Only 5.8\% said they had access to private boreholes, communal wells (4.0\%), private wells (13.8\%), and dams (21.4\%). Median water consumption per household per day was $140 \mathrm{~L}$ or $20.9 \mathrm{~L}$ per person, and average trip time spent fetching water both ways per household (no participant households were tap fed) was $111 \mathrm{~min}$ (median $60 \mathrm{~min}$ ), and $14 \mathrm{~min}$ per person per day. Total storage capacity per household for our sample was 239.4 $\mathrm{L}$ (median $160 \mathrm{~L}$ ), as aggregated by totalling the number of portable storage containers.

\section{RESULTS}

\section{Perception of waterborne illness}

Participants were asked if they, or any of their family members, have ever become ill from the water they drink ('Yes' or 'No'). This dichotomous variable does not provide the actual incidence of waterborne illness in the study area, but rather participants' perceptions of encountering waterborne illness. According to the response, 74 of the total 224 participants (33.0\%) reported experienced illness from drinking water. Of those experiencing illness attributed to water they consumed, the majority stated that the illness occurred in the past 2 years (96.0\%). Water drawn from surface water resources, such as a pond or a stream, constituted $93.2 \%$ of the sources from which participants reported becoming ill. The symptoms participants reported having when ill were diarrhoea (97.3\%), vomiting (12.2\%), or stomach pain $(6.8 \%)$, with many reporting a combination of symptoms (See Fig. 2). The majority of those who experienced illness sought treatment at a local clinic (90\%), and the remaining $10 \%$ used charcoal or another home remedy to treat their illness. Of those who experienced diarrhoea, 70.8\% of diarrhoea was considered to be from pond water, while about $23.6 \%$ came from a stream.

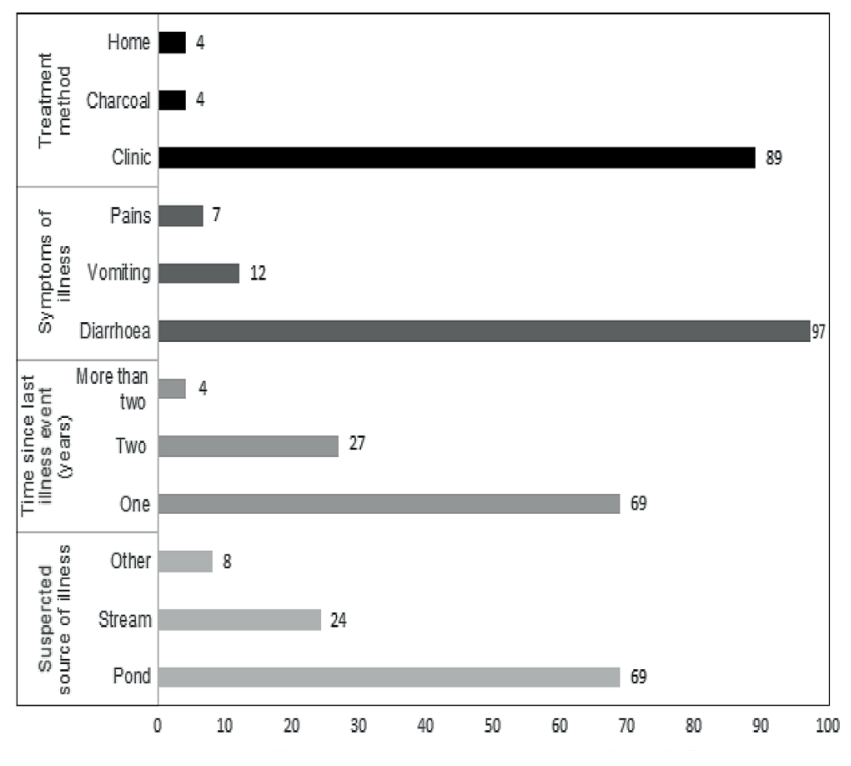

Figure 2

Of those respondents who reported experiencing waterborne illness, shown here is their responses to questions about water treatment and method, symptoms of illness experienced, time since the experienced illness, and the suspected source of the illness

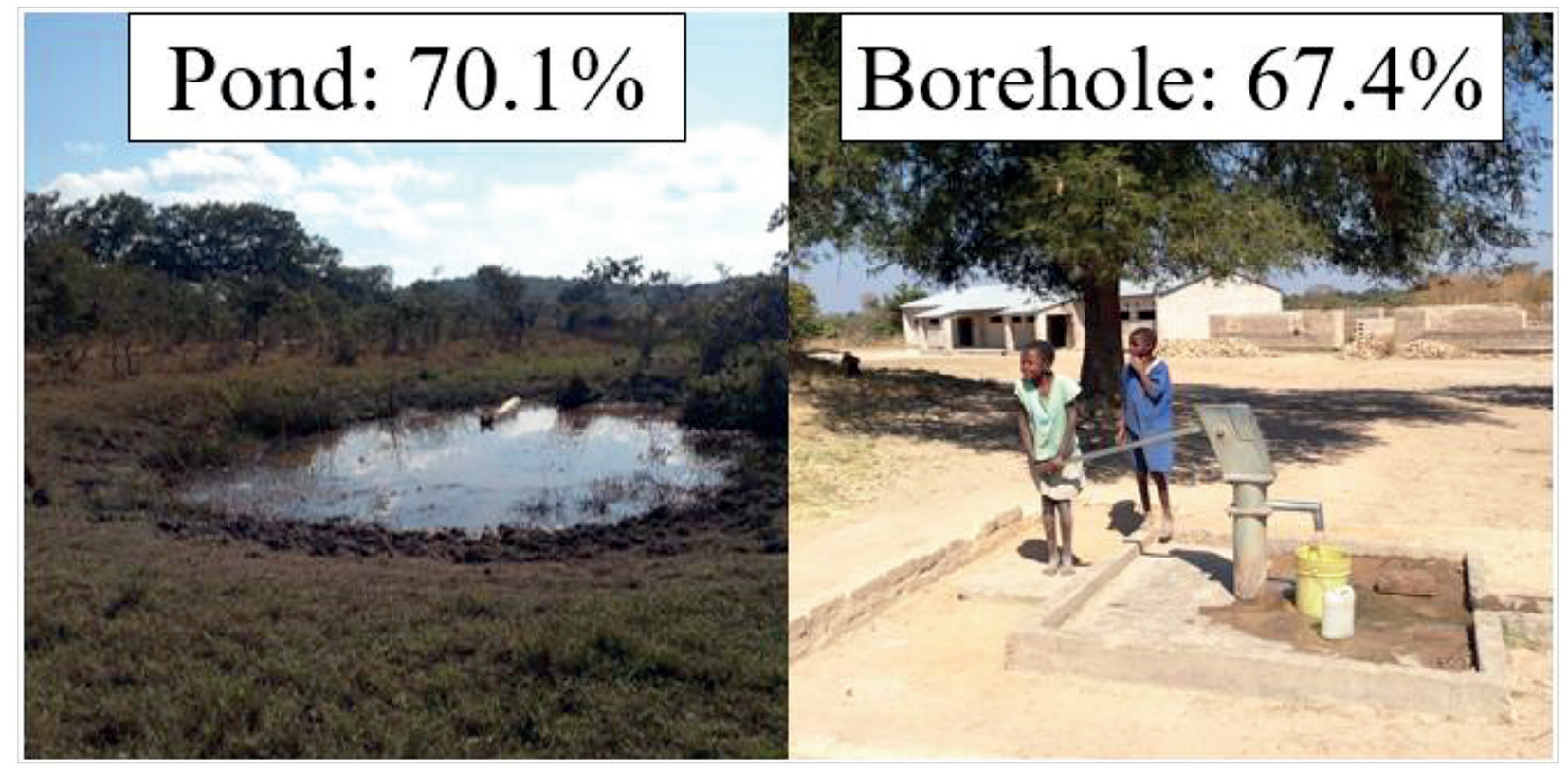

Figure 1

The two most common water resource types reported by participants: a pond (an unimproved water resource); and a borehole (an improved water resource) 


\section{Mapping incidence of illness}

Using our georeferenced survey data and a Getis-Ord Gi analysis procedure (or hotspot analysis), we can see where perceptions of waterborne illness occurring are most dense (see Fig. 3). This procedure looks at each data point within the context of neighbouring data points by comparing the local sum of a specific characteristic (in this case reported incidence of waterborne illness) proportionally to the sum of all such characteristics. The result is a Gi Z-score that tells us where high or low values of reported waterborne illness cluster spatially. Negative values represent areas where reported waterborne illness is low, and positive values represent areas where reported waterborne illness is high. Brighter colours represent areas where clustering - or similar responses - is more intense (i.e. a hotspot), and more neutral colours depict areas where less clustering - or dissimilar responses - are present. The results tell us that participants who live further away from the Choma city centre are more likely to perceive experiencing waterborne illness than those who live closer to town. This is especially true for those who live southwest of Choma, which is where the driest region of Southern Province, and of Zambia, begins, and continues to the Zambia-Zimbabwe border (Chisanga and Hamazakaza, 2008). This area is colloquially known as the 'Valley' and sits at the base of the plateau upon which the majority of Choma District lies.

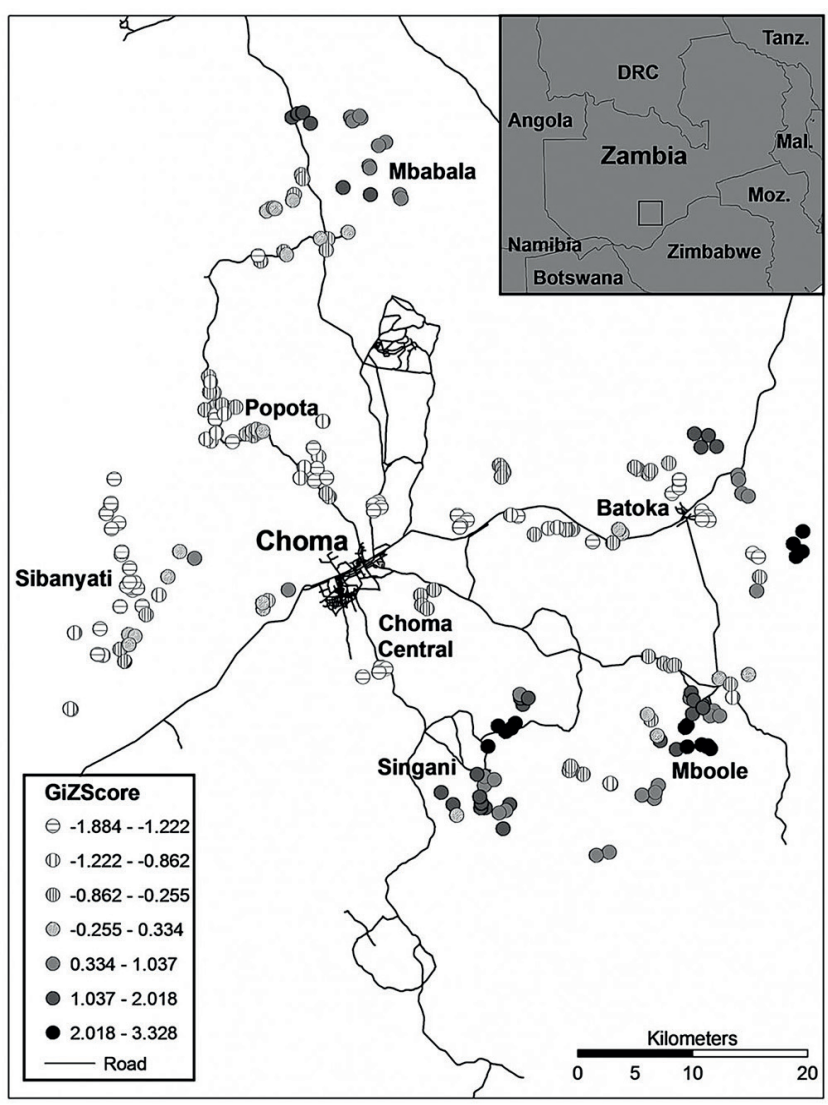

Figure 3

This map depicts a hotspot analysis of perceptions of waterborne illness. Hotspots (depicted with brighter colours) are present for both negative and positive Gi Z-score values, representing where neighbours are more similar - or where clustering occurs.

\section{Modelling illness}

I use a logistic regression procedure to model responses (Yes, No) of whether a participant perceived having been ill from their drinking water or not, which is the dependent variable of interest. The model is used to explore possible correlates to perceived illness. Logistic regression was used instead of a correlation matrix given the ability of the model to more fully explore the relationship between variables by providing more reliable estimates of the relationship between variables than basic correlation alone. I do not report the coefficient of determination (pseudo $R^{2}$ value) as a measure of the predictive ability of the model because I am more interested in understanding the relationships between the dependent and independent variables than I am in the predictive power of the model. Note: I tested a random effects multilevel logistic regression, as the nested nature of the data facilitate this making theoretical sense (4 participants per zone, 8 zones per camp, 8 camps), but the results are near identical and the simpler logistic regression model demonstrated a better fit. Additionally, I investigated the interaction between variables in two ways: (i) a simple correlation matrix to see the correlation between different independent variables; and (ii) I tested for multicollinearity between variables by calculating variance inflation factors (VIFs) and tolerance values for all variables included in the model. The final model (the one presented in this paper) has VIF and tolerance values well within commonly accepted limits.

\section{Independent variables used in the model}

Water storage (L/household member): Participants were asked how many water storage containers they have at their home and the size (in L) of each. These values were summed to obtain total water storage capacity for the participants' household. 'Water storage' is calculated by using total household water storage divided by household members, yielding water storage capacity per household member. The total water storage capacity of a household can significantly impact its ability to respond to water shortages and water quality issues (Onigbogi and Ogunyemi, 2014). The average storage size was $30.1 \mathrm{~L} /$ household member. The distribution of 'water storage' ranged from a minimum value of $3.7 \mathrm{~L} /$ household member, to a maximum value of $438 \mathrm{~L} /$ household member.

Water treatment (TreatV; Yes or No): Participants were asked whether they treat their drinking water or not prior to consumption. If they said yes, they were then asked what method of treatment they used. All responses were either boiling, applying chlorine, or a combination of the two. In total, $42.0 \%$ of participants reporting treating their drinking water; of these, $77.9 \%$ applied chlorine and $35.8 \%$ boiled their water (the sum is greater than $100 \%$ because some participants used both methods).

Water fetch time per person per day (WFI): Participants were asked how many trips their household makes each day to fetch water, the number of people in their household, and the time it takes (in minutes) to travel to their main water source. These three variables were used to calculate the time spent fetching water per person each day (no. of trips $\mathrm{x}$ time per round-trip/no. of household members). The more time a household has to spend fetching water, the more likely they are to feel the impacts of water scarcity on household activities and productivity (Gemenne et al., 2014; Wutich and Ragsdale, 2008). Additionally, those who have to spend a relatively longer 
time fetching water may be less apt to spend additional time treating their water prior to consumption.

Water use per person per day (WUI, L per household member per day): Participants were asked to estimate how many litres of water their household uses each day. Their estimates were used to calculate a per capita use value by dividing their estimate by the total number of household members (total no. of L / no. of household members). Here, water use includes drinking water consumption and other household water needs such as cooking and cleaning. The average water use per person per day was $20.9 \mathrm{~L}$, with a distribution that ranged from a minimum value of $1.14 \mathrm{~L}$, to a maximum value of $66.67 \mathrm{~L}$.

Water sources: Participants were asked to list their main sources of water. These responses were recorded and then later sorted into two categories: surface water (dam, pond and river), and groundwater (communal borehole, private borehole). After categorizing responses into these two types, $71.4 \%$ of participants had access to a groundwater resource and $89.7 \%$ had access to a surface water resource. While dams and some manmade ponds in the study area are 'improved' by a built-structure of some form, all of the dams and ponds in the study area were similarly exposed to contamination as there were no protective barriers in place. Given these local contexts, rather than categorizing water resources solely on whether they have received some form of built improvement, employing ground vs. surface water as the dividing line was more cleanly supported by the data. Two new variables were created to account for the two types of water sources available for household water use and the intensity of water use by each household. 'Surface water ${ }^{\star}$ WUI' interacts with surface water available (Yes or No) and water use per household member per day. 'Ground water*WUI' interacts with surface water available (Yes or No) and water use per household member per day. The interaction of water source with total usage per household member per day is, firstly, a measure of whether the participant has access to surface water or groundwater or not; and then a measure of water use intensity of that resource. The mean values for these two variables are 18.84 (standard deviation $=$ 11.99 ) and 14.44 (standard deviation $=12.61$ ) L per household member per day, respectively. By creating this variable we are able to see how having access to either surface water or groundwater impacts a participant's relative reliance on either source to meet their household water needs and what effect this might have on their perception of waterborne illness (among other factors), as has been demonstrated in other work (See Workman and Ureksoy, 2017). Given our previous discussion of the benefits of groundwater compared to surface water, this is an important differentiation to draw out in the analysis.

Household water needs (hh_water): Participants were asked whether their household water needs had been met in the past 10 years or not. If household water needs are not met by primary water resources, participants are more likely to use water resources of lower quality (i.e. pond water) in order to satisfy household water needs, which increases the risk of waterborne illness occurring. More than half (68\%) of participants reported that their household water needs were not met in the past 10 years. Participants were asked about the past 10 years, rather than just the past year, in order to capture the effects of changes in water access and perceptions of illness over time. Though not included in this model, participants were asked if their water needs had been met in the past year; almost all participants (93\%) said that their needs were not met due to a severe drought that occurred that year. By including the
10 -year water needs response variable in the model, rather than just the past year's water needs being met or not, the model speaks to a longer-term trend in water access as opposed to just capturing the effects of a single - albeit severe - drought event.

Distance to Choma: This variable measures the Euclidian distance (the straight-line distance) from each participant's household to the centre of Choma town (see Fig. 3). This variable is a proxy for how far the participant has to travel to be able to access Choma town and the services available there (which includes access to government services, a large market where most sell their goods and purchase manufactured items, etc.). The furthest distance a participant lived was $38.9 \mathrm{~km}$; the average distance was $23.5 \mathrm{~km}(\mathrm{SD}=8.9 \mathrm{~km})$.

Distance to clinic: This variable measures the Euclidian distance (the straight-line distance) from each participant's household to the nearest government-provided health clinic (Fig. 3). This variable measures for how far a participant has to travel to access public health services. The furthest distance a participant lived was $36.3 \mathrm{~km}$; the average distance was $14.8 \mathrm{~km}$ $(\mathrm{SD}=9.2 \mathrm{~km})$.

Food ration: Participants were asked whether their household had to ration their food in the past 5 years. Food scarcity can lead to decreased rates of individual nutrition, which in turn leads to a suppressed immune system and the potential for increased incidence of waterborne illness (Hadley and Wutich, 2009; Hanjra and Qureshi, 2010; UNICEF, 2009). The relationship between food rationing and illness is also very important because both rely on rainfall: field crop and garden crop production need rain to water the crops and refill the dambos used to irrigate gardens; most of the water that people are consuming comes from surface waters whose quality and quantity is directly tied to rainfall. If rainfall is inadequate due to drought or flooding in a given year, then we would expect that both food rationing and incidence of illness will increase accordingly. Of participants, $44.6 \%$ reported having to ration their food in the past 5 years.

Household size, education, age, and gender: The survey asks several demographic questions that function as control variables in the model. Past research has demonstrated that potential relationships exist between these variables and illness outcomes. For example, age has been shown to have a direct relationship with potential illness. For example, diarrhoea, a common symptom of waterborne illness, is shown to pose an increased health risk for children under the age of 5 (UNICEF, 2009; WHO, 2016). Gender studies have demonstrated that the presence of dichotomous gender roles (male/female) impacts each person's perception or interaction with water issues resulting in divergent experiences (Dankelman, 2002; Wutich, 2009). Finally, formal schooling has been associated with increased understandings of waterborne illness and water treatment awareness, and thus increased education has been shown to decrease the risk of waterborne illness (WeziakBialowolska, 2016; Xiong et al., 2016). The average age was 48.26 years old, the average education level attained was 7.5 years of schooling, and $40.2 \%$ of participants were female.

\section{Model results}

Table 1 shows the model results for the logistic regression procedure used to model responses (Yes, No) to whether a participant perceived having been ill from the water they drink or not.

The model results indicate that several important relationships exist between the independent variables and whether or 
not a participant perceived having been ill from the water they drink. First, if a participant reported a surface water resource as one of their main sources of water, then they are significantly more likely to perceive having been ill from their drinking water $(p<0.001)$. The connection between surface water and illness is well-known by participants as will be discussed later. In contrast, if a participant reported groundwater as a main source of water, they were significantly less likely to report being ill from the water they drink $(p<0.05)$. These findings demonstrate that having access to groundwater or not plays a significant and important role in whether participants are more like to perceive having been ill from the water they drink, and they are consistent with our previous discussion about the benefits of groundwater resources. Again, these statistical findings are consistent with narratives from participants, as will be drawn out in the discussion section.

A second notable finding is that the further a participant lives from Choma, the more likely they are to perceive having been ill from their drinking water. For every $1-\mathrm{km}$ increase in distance from the city centre that a participant lives, the model suggests a $9 \%$ increase in the likelihood that a participant will perceive having been ill from the water they drink. This result may represent several factors that are associated with living further away from the urban centre. For example, participants who live further away from the urban centre may have reduced access to markets where water treatment implements are sold. This result may also demonstrate a decrease in the level of water development works further away from the city centre.

Finally, if a participant had to ration their food this past year, they are 3.3 times more likely to also report having been ill from their drinking water. Rationing of food occurs for many reasons, including having had a poor field crop harvest this past season, lack of access to water for growing garden crops which can be used to supplement one's diet, or an increase in food prices at markets resulting in an inability to purchase additional foods. Again, these are just a few reasons as to why one might have to ration one's food, and there may be more than one at play. We will return to this important relationship in the discussion section.

\section{DISCUSSION}

In reviewing the model results, we find that multiple variables have a significant and substantively important relationship with perceptions of waterborne illness. Of these variables, five are directly concerned with water (surface water, groundwater, water storage, and household water needs); two are demographic variables (distance to Choma, education); and one (food rationing) is not directly associated with waterborne illness but can result in conditions conducive to waterborne illness occurring. It is not possible for us to measure the actual incidence rate of waterborne illness among our participants or if the source of a given instance of illness is from a water resource or not. However, our results clearly demonstrate that participant's perceptions of waterborne illness are significantly connected to where people are getting their water, how much water they have access to, and whether their water needs are being satisfied or not.

One of the most important factors in determining the likelihood of a household experiencing waterborne illness is the type of water resource(s) they have access to as surface water resources have an increased pathogen carrying likelihood compared to groundwater. Abramson et al. (2013) tested E. coli contamination in different water sources in Southern Zambia.

\begin{tabular}{|c|c|c|}
\hline \multicolumn{3}{|c|}{$\begin{array}{l}\text { TABLE } 1 \\
\text { Parameter estimates for the perception } \\
\text { waterborne illness using a basic logistic } \\
\text { regression modelling procedure. }\end{array}$} \\
\hline \multirow[t]{2}{*}{ Parameters } & \multicolumn{2}{|c|}{$\begin{array}{c}\text { Perception of } \\
\text { waterborne illness }\end{array}$} \\
\hline & Estimate & SE \\
\hline Intercept & $-3.448^{\star *}$ & 1.507 \\
\hline $\begin{array}{l}\text { Surface water consumed per person } \\
\text { per day }(\mathrm{L})\end{array}$ & $0.090^{* * * *}$ & 0.024 \\
\hline $\begin{array}{l}\text { Ground water consumed per person } \\
\text { per day (L) }\end{array}$ & $-0.044^{* *}$ & 0.019 \\
\hline Water storage per person per day (L) & $-0.031^{\star *}$ & 0.014 \\
\hline $\begin{array}{l}\text { Water fetch time per person per day } \\
\text { (min) }\end{array}$ & 0.004 & 0.010 \\
\hline Water treatment & 0.443 & 0.418 \\
\hline $\begin{array}{l}\text { Household water needs met in past } \\
10 \text { years }\end{array}$ & $-0.847^{\star}$ & 0.473 \\
\hline Distance to clinic $(\mathrm{km})$ & -0.019 & 0.028 \\
\hline Distance to Choma $(\mathrm{km})$ & $0.086^{\star * *}$ & 0.031 \\
\hline Food rationing & $1.191^{* * *}$ & 0.390 \\
\hline Household size & 0.021 & 0.045 \\
\hline Age (year) & $<0.001$ & 0.014 \\
\hline Education (year) & $-0.117^{\star}$ & 0.069 \\
\hline Gender & 0.238 & 0.423 \\
\hline
\end{tabular}

His results indicate that improved water sources (groundwater sources such as a borehole) contained no E. coli contamination, one of the main pathogens for diarrhoea; however, he found that surface water resources (pond, river, or a dam) were heavily contaminated. This result is consistent with the findings of our study: participants accessing groundwater resources share a strong negative relationship with perceived illness, and participants accessing surface water resources share a strong positive relationship with perceived illness. However, most of our participants still use surface water more often than not, so we need to understand why this is the case, and how this affects the daily lives of our participants and their experience with waterborne illness.

The benefits of improved water resources are clearly identified here, a reality not lost on participants who frequently noted the benefits of having access to an improved water resource in their open-ended responses. For example, many participants said that "If you have a borehole, you don't have to search for water and can focus on your own needs. But if the borehole breaks or it is too far from the home, people just stick to ponds and the community suffers. Then, in the dry season when it is hot and dusty, people suffer water hardship even more." Surface water resources remain a primary source for satisfying household water needs in Southern Province, Zambia. According to UNICEF (2016), only 74\% of the rural population in Zambia has access to improved water sources that provide clean drinking water (which includes both improved ground and surface water resources), a figure that is lower than the world average by country which is $91 \%$ having access (WHO, 2016). Our results indicate that our participants have greater improved water resource access than the Zambian national average; despite this, $50.4 \%$ of our participants still 
reported that their water needs had not been met over the past 10 years.

Even though our participants have more access to improved water resources compared to other parts of Zambia, their water needs are still not being met. This reinforces the claim that simply having access to a water resource is not sufficient to determine if (i) a household's water needs will be met; or (ii) if a household will experience negative effects from water despite having access to it, such as the effects of experiencing waterborne illness. If the improved source is too distant from the home, lines at the borehole are too long, or it becomes inoperable - which participants said happens often either from the water table dropping in the dry season or the hand pump mechanism breaking - participants may still have 'access' to that source but in reality it is of no added benefit to their daily lives. Similarly, a participant may have consistent access to pond water, but if that water is contaminated by pathogens which increase with temperature or by shared use with livestock because their normal watering holes have dried up, then access alone may not benefit household water needs. As one participant said, "I have a pond that I drink from all year because it is in the valley so always has water. But in the dry season it turns brown and murky from dust and algae, so it is difficult but what else can I do? Our village has 27 households and no borehole. We have water from ponds, but water should be clean and ours is not!" Even if a person has access to - and employs - water treatment mechanisms, they are not always effective, employed properly, or convenient. As the model results indicate, participants who reported treating their water were not significantly less likely to experience waterborne illness compared to those who reported that they did not treat the water they drink. Additionally, as the model results show, water storage capacity significantly influences whether a participant reported experiencing waterborne illness. Having water storage capacity can both increase the amount of water that can be stored at a household and increase how much water can be transported to the residence when fetching water. Water storage capacity thus acts as a flexibility mechanism because if water is in short supply at the source this can be mitigated for a period by having extra water at home, and it reduces the total amount of time a household has to spend fetching water allowing them to invest that time in other practices to include treating their water.

That participants who live further away from Choma Town are significantly more likely to report experiencing waterborne illness is telling of several issues and potential points of intervention. For example, access to improved water resources in Choma decreases the further away from the urban centres you live or travel, paralleling the taper of development work both by the Zambian government and NGOs (Chisanga and Hamazakaza, 2008). Participants who lived in more distant areas from the Choma town centre frequently noted the lack of development they experienced, or had access to, relative to villages and camps more proximal to Choma town. One participant explicitly stated, "The government and NGOs only stick to roads and the town, and don't come to where people who actually need development live. Some say they are afraid to break their vehicles, some say it is because it costs too much to get out here. I think they are either lazy or don't care." That development is occurring at increased levels closer to the urban centre makes intuitive sense as the input requirements (fuel for travel, time spent in transit, etc.) for development increase with greater distance from the resource base (in this case, Choma town). However, this persistent pattern in Choma
District has created sizable gaps in improved water resource access, among other services provided by the government and NGOs. Given this, future water development projects in the area should look to target more distant areas, particularly those facing elevated incidence of waterborne illness as shown in Fig. 3. Each time we began to work in a new camp, our research team would drive and walk the full extent of the camp with the camp officer and the community agricultural chairman. Our observations of the landscape were consistent with our participants in that we also saw first-hand fewer boreholes, dams, health clinics, improved roads, and other visual signs of development as we travelled further away from Choma town and the few paved roads in the area.

Interestingly, time spent fetching water (variable 'water fetch time per person per day) is not demonstrated to be statistically significant. Intuitively it would seem that having to spend more time each day collecting water would indicate decreased overall water access, and therefore potentially higher rates of perceived waterborne illness. However, responses from many participants complicate this relationship and demonstrate that preference is not always given to clean water, rather it is sometimes given to more expedient water even if it is assessed to be of lower quality. For example, Gift, a young adult male participant, noted that "Some days I will travel the extra distance to the borehole by the school, or if I am going to pass it anyways I may stop there. But the pond is close, so as long as it has water I go there. It is too much energy to try and get all the way to the borehole every time I need water, and I am used to the dirt in the pond." Gift's sentiments indicate that time spent fetching water is a more complicated expression of water access, and potential resultant illness from drinking water, than the statistical model alone can account for.

The connection between food security and perceptions of illness is also revealed by our analysis and deserves explicit attention here. Almost half of our participants reported that they had to ration their food in the past 5 years. When asked why, participants almost ubiquitously stated it was due to poor rainfall for their field crop and garden crop needs: there had not been enough rain to water their field crops or to fill their ponds or dambos to water their garden crops with. Participants also noted that they most often had to ration food in the dry season when their stores from the past year's field crops run low or out and they are unable to produce garden crops to make up the deficit: peak food stress and water stress occur at the same time. People who rationed food said they either shifted from 3 to 2 or 1 meals a day, and/or reduced overall portions of the meal. Others said they might switch from nshima as the meal base (a staple food in Zambia made from maize flour) to porridge or samp, which essentially means more water and less maize flour, and subsequently less calories. If a person is malnourished from having to ration their food, they are more susceptible to illness such as waterborne illness. In dry season conditions, participants not only endure water quality and quantity issues, they also must deal with food shortages and potential malnutrition: these are co-occurring and mutually reinforcing threats to life and livelihood.

The positive relationship between a participant's distance from Choma and their perceptions of waterborne illness - as well as other factors such as food shortages - may be affected by their lack of access to health services and medications, water treatment mechanisms, and other goods that are more readily accessible to individuals living closer to Choma town. The findings from the statistical model, as well as from interviews with the camp officers and the head of the Choma 
District Water Authority, indicate that increased market access, health services, and government support, either through public transit improvement or the development of satellite markets and services, may decrease perceptions of waterborne illness. For example, the deployment of mobile health services to areas with limited access to health clinics can help combat perceived waterborne illness by providing medicines and nutritional supplements that improve an individual's immunoreactivity to waterborne diseases (Carvajal-Vélez et al., 2016). The distribution of preventative measures such as water treatment mechanisms (i.e. chlorine tablets or water filter) and hygiene implements will likely also help to this end, as people who live further away from Choma - who are also those less likely to have access to a borehole - more often reported that they would use water treatment mechanisms if they had access to them but that the market was too far away to get them as often as needed. Finally, as our model results show (See Table 1), the more water storage capacity that a participant has access to, the less likely they are to perceive having experienced waterborne illness. Household water storage capacity - such as plastic drums or other large reservoirs that can be filled either from rainwater or other sources - can act as a flexibility mechanism by providing participants access to water in particularly acute shortage events. In areas where a borehole is not feasible in the immediate future, the delivery of water storage devices may be the next best alternative in the short term. Development functions of this sort, paired with further groundwater resource development, which has been demonstrated above to be of significant importance in the battle against waterborne illness, are the optimal points of initiation for beginning to focus in on waterborne illness. The use of innovative, dualpronged methods to combat waterborne illness, such as provisioning water storage capacity and groundwater access, are essential to effectively respond to expected increases in waterborne illness due to increased water insecurity as a function of global climate change.

\section{CONCLUSION}

Incidence of waterborne illness is likely to increase as a function of climate change-driven water issues in SubSaharan Africa because surface water resources - the source most often used by our participants - are vulnerable to drought and flood events, increased temperatures, and other climate-driven impacts (Delpla et al., 2009; Edenhofer et al., 2014; Pachauri et al., 2014; Prüss-Ustün et al., 2014)2014; Pr|\uc0\|u252\{\}ss-Ust \uc0\|u252\{\}n et al., 2014. Here, I demonstrated how individual perceptions of waterborne illness are tightly coupled with perceptions of water needs, water flexibility (water storage capacity and resources available), water use intensity, and access to various services. The intersecting relationships identified here - such as primary water source and total water usage - each present an opportunity for policy, or other means of intervention, to reduce experienced and perceived waterborne illness. By identifying these relationships, this research informs future policy and development decision making, promoting more efficient and effective solutions to orienting on waterborne illness and its impacts. Specifically, I show that (i) water resource development needs to push out into areas further from urban centres and roads where development work has been absent for ease of access and where waterborne illness is perceived to be greatest as a result; (ii) from the experience of our participants, waterborne illness is intricately related to other issues such as food security, so any intervention or policy should be designed with these other intersecting factors in mind; and (iii) I demonstrate a novel way to model perceptions of waterborne illness and parse in a more detailed way the relationship between a participant and the water resources they access and rely on. Future research should target better understandings of the relationship between waterborne illness and distance from an urban centre, improved methods for expeditious water treatment, and investigate ways to increase improved water resource development and access. To achieve the UN SDG6 goal of all people having access to clean and safe drinking water, it is essential to recognize and integrate local level understandings to global scale interventions. This article represents a first step towards understanding how water security and perceptions of illness intersect in everyday life for rain-fed subsistence farmers in Southern Province, Zambia, specifically, and more generally for rain-fed subsistence farmers worldwide.

\section{NOTE}

All participant names included in this article are pseudonyms. This is done to protect the identities of participants of the study.

\section{ACKNOWLEDGEMENTS}

Thank you to my partners in the Zambian Agricultural Research Institute (ZARI) in Lusaka and Mochipapa. In particular, I thank Allan Chilenga and Kafula Chisanga for their valuable insights and assistance. I thank our enumerators, Godwin Siagande and Rose Kisananga, and each respondent who generously gave their time to completing the survey. I also thank Kurt Waldman, Paul McCord, and, most especially, Yu Song for research assistance. This research is supported by funding from Indiana University Office of Sustainability who provided a Research Development Grant to Richard Marcantonio, and the National Science Foundation Water, Sustainability, Climate grant (SES 1360463). This research has been approved by Indiana University's Institutional Review Board at the Office of Research Administration; and informed consent was received from all respondents. Respondents were not paid for their participation in our study. Finally, I want to thank two anonymous reviewers, especially Reviewer 2 whose detailed assessment and insightful comments truly enhanced the quality of this paper.

\section{REFERENCES}

ABRAMSON A, BENAMI M and WEISBROD N (2013) Adapting Enzyme-Based Microbial Water Quality Analysis to Remote Areas in Low-Income Countries. Environ. Sci. Technol. 130829091443004. https://doi.org/10.1021/es402175n

ADGER N (2010) Climate Change, Human Well-Being and Insecurity. New Polit. Econ. 15 275-292. https://doi. org/10.1080/13563460903290912

CARVAJAL-VÉLEZ L, AMOUZOU A, PERIN J, MAÏGA A, TAREKEGN H, AKINYEMI A, SHIFERAW S, YOUNG M, BRYCE J and NEWBY H (2016) Diarrhea management in children under five in sub-Saharan Africa: does the source of care matter? A countdown analysis. BMC Public Health 16. https://doi.org/10.1186/ s12889-016-3475-1

CHISANGA K and HAMAZAKAZA P (2008) Farmer perceptions of climate change. Zambian Agricultural Research Institute, Lusaka.

CONFALONIERI U, MENNE B, AKHTAR R, EBI K, HAUENGUE M, KOVATS RS, REVICH B and WOODWARD A (2007) Human health. Climate Change 2007: Impacts, Adaptation, and 
Vulnerability. Contribution of Working Group II to the Fourth Assessment Report of the Intergovernmental Panel on Climate Change. International Panel on Climate Change. Cambridge University Press, Cambridge, UK.

CSO (Central Statistics Office, Zambia) (2010) 2010 Census of Population: National Analytical Report, Zambia. Zambian Central Statistics Office, Lusaka.

DACO (2015) Farmer Register: Choma District, Southern Province. Zambian Agricultural Research Institute, Choma town.

DANGOUR AD, WATSON L, CUMMING O, BOISSON S, CHE Y, VELLEMAN Y, CAVILL S, ALLEN E and UAUY R (2013) Interventions to improve water quality and supply, sanitation and hygiene practices, and their effects on the nutritional status of children. Cochrane Database Syst. Rev. CD009382.

DANKELMAN I (2002) Climate change: Learning from gender analysis and women's experiences of organising for sustainable development. Gend. Dev. 10 21-29. https://doi. org $/ 10.1080 / 13552070215899$

DELPLA I, JUNG A-V, BAURES E, CLEMENT M and THOMAS $O$ (2009) Impacts of climate change on surface water quality in relation to drinking water production. Environ. Int. 35 1225-1233. https://doi.org/10.1016/j.envint.2009.07.001

EDENHOFER O, PICHS-MADRUGA R, SOKONA Y, FARAHANI E, KADNER S, SEYBOTH K, ADLER A, BAUM I, BRUNNER S, EICKEMEIER P and co-authors (2014). Climate Change 2014: Mitigation of Climate Change. Contrib. Work. Group III Fifth Assess. Rep. Intergov. Panel Clim. Change. United Nations, Geneva.

FAO (2009) Farmer Input Support Response Initiative (FISRI) to Rising Prices of Agricultural Commodities in Zambia. FAO, Rome.

FEWTRELL L, KAUFMANN RB, KAY D, ENANORIA W, HALLER L and COLFORD JM (2005) Water, sanitation, and hygiene interventions to reduce diarrhoea in less developed countries: a systematic review and meta-analysis. Lancet Infect. Dis. 5 42-52. https://doi.org/10.1016/S1473-3099(04)01253-8

GEMENNE F, BARNETT J, ADGER N and DABELKO GD (2014) Climate and security: evidence, emerging risks, and a new agenda. Clim. Change 123 1-9.

GÜNTHER I and FINK G (2010) Water, Sanitation and Children's Health. Prospects. The World Bank, Washington, D.C.

HADLEY C and FREEMAN MC (2016) Assessing reliability, change after intervention, and performance of a water insecurity scale in rural Ethiopia. Food Secur. 8 855-864. https://doi.org/10.1007/ s12571-016-0599-1

HADLEY C and WUTICH A (2009) Experience-based measures of food and water security: Biocultural approaches to grounded measures of insecurity. Hum. Organ. 68 451-460. https://doi. org/10.17730/humo.68.4.932w421317680w5x

HANJRA MA and QURESHI ME (2010) Global water crisis and future food security in an era of climate change. Food Polic. 35 365-377. https://doi.org/10.1016/j.foodpol.2010.05.006

JEPSON W, BUDDS J, EICHELBERGER L, HARRIS L, NORMAN E, O'REILLY K, PEARSON A, SHAH S, SHINN J, STADDON C and co-authors (2017). Advancing human capabilities for water security: A relational approach. Water Secur. 1 46-52. https://doi. org/10.1016/j.wasec.2017.07.001

MEKONNEN MM and HOEKSTRA AY (2016) Four billion people facing severe water scarcity. Sci. Adv. 2 e1500323-e1500323. https:// doi.org/10.1126/sciadv.1500323

MORRIS T, STANFORD RW, BIGAS H and ZAFAR A (2012) The Global Water Crisis: Addressing an Urgent Security Issue. United Nations University Press, Geneva.

MTAMBANENGWE F, MAPFUMO P, CHIKOWO R and CHAMBOKO T (2012) Climate change and variability: smallholder farming communities in Zimbabwe portray a varied understanding. Afr. Crop Sci. J. 20 227-241.

MURPHY HM, PRIOLEAU MD, BORCHARDT MA and HYNDS PD (2017) Review: Epidemiological evidence of groundwater contribution to global enteric disease, 1948-2015. Hydrogeol. J. 25 981-1001. https://doi.org/10.1007/s10040-017-1543-y

MURRAY CJL and LOPEZ AD (2013) Measuring the global burden of disease. N. Engl. J. Med. 369 448-457. https://doi.org/10.1056/ NEJMra1201534

ONIGBOGI O and OGUNYEMI O (2014) Effect of storage containers on quality of household drinking water in urban communities in Ibadan, Nigeria. Int. J. Public Health Sci. 3 253-258.

PACHAURI RK, ALLEN MR, BARROS VR, BROOME J, CRAMER W, CHRIST R, CHURCH JA, CLARKE L, DAHE Q, DASGUPTA P and co-authors (2014) Climate Change 2014: Synthesis Report. Contribution of Working Groups I, II and III to the Fifth Assessment Report of the Intergovernmental Panel on Climate Change. IPCC, United Nations, Geneva.

PRÜSS-USTÜN A, BARTRAM J, CLASEN T, COLFORD JM, CUMMING O, CURTIS V, BONJOUR S, DANGOUR AD, DE FRANCE J, FEWTRELL L and co-authors (2014) Burden of disease from inadequate water, sanitation and hygiene in low- and middleincome settings: a retrospective analysis of data from 145 countries. Trop. Med. Int. Health 19 894-905. https://doi.org/10.1111/tmi.12329

PULLAN RL, FREEMAN MC, GETHING PW and BROOKER SJ (2014) Geographic inequalities in Sub-Saharan Africa: Mapping and spatial analysis of cross-sectional survey data. PLoS Med. 11 e1001626. https://doi.org/10.1371/journal.pmed.1001626

SOBSEY MD (2002) Managing Water in the Home: Accelerated Health Gains from Improved Water Supply. World Health Organization, Geneva.

STERN RD and COOPER PJM (2011) Assessing climate risk and climate change using rainfall data - a case study from Zambia. Exp. Agric. 47 241-266. https://doi.org/10.1017/S0014479711000081

STEVENSON EGJ, GREENE LE, MAES KC, AMBELU A, TESFAYE YA, RHEINGANS R and HADLEY C (2012) Water insecurity in 3 dimensions: An anthropological perspective on water and women's psychosocial distress in Ethiopia. Soc. Sci. Med. 75 392-400. https://doi.org/10.1016/j.socscimed.2012.03.022

STRINGER LC, DYER JC, REED MS, DOUGILL AJ, TWYMAN C and MKWAMBISI D (2009) Adaptations to climate change, drought and desertification: local insights to enhance policy in southern Africa. Environ. Sci. Polic. 12 748-765. https://doi.org/10.1016/j. envsci.2009.04.002

TSCHAKERT P (2007) Views from the vulnerable: Understanding climatic and other stressors in the Sahel. Glob. Environ. Change $\mathbf{1 7}$ 381-396. https://doi.org/10.1016/j.gloenvcha.2006.11.008

UN (United Nations) (2010) The Human Right to Water and Sanitation. United Nations, Geneva.

UN (United Nations) (2016a) United Nations Social and Economic Council: Progress towards the Sustainable Development Goals. United Nations, New York.

UN (United Nations) (2016b) Clean Water and Sanitation: Why it Matters. United Nations, New York.

UNICEF (2009) Diarrhoea: Why Children Are Still Dying And What Can Be Done. UNICEF, New York.

UNICEF (2015) Progress on Sanitation and Drinking Water. UNICEF and World Health Organization Joint Partnership, Geneva.

UNICEF (2016) UNICEF Zambia - Resources - Water, Sanitation, and Hygiene. UNICEF, Geneva.

WAITE RC, VELLEMAN Y, WOODS G, CHITTY A and FREEMAN $M C$ (2016) Integration of water, sanitation and hygiene for the control of neglected tropical diseases: a review of progress and the way forward. Int. Health 8 i22-i27. https://doi.org/10.1093/ inthealth/ihw003

WEZIAK-BIALOWOLSKA D (2016) Spatial variation in EU poverty with respect to health, education and living standards. Soc. Indic. Res. 125 451-479. https://doi.org/10.1007/s11205-014-0848-7

WHO (2016) Water-related diseases: information sheets. World Health Organization, Geneva.

WHO (2017a) Progress on Drinking Water, Sanitation and Hygiene: 2017 Update and SDG Baselines. World Health Organization and UNICEF, Geneva.

WHO (2017b) Safely Managed Drinking Water - Thematic Report on Drinking Water 2017. World Health Organization, Geneva.

WORKMAN CL and UREKSOY H (2017). Water insecurity in a syndemic context: Understanding the psycho-emotional stress of water insecurity in Lesotho, Africa. Soc. Sci. Med. 179 52-60. https://doi.org/10.1016/j.socscimed.2017.02.026

WSP (2012) Economic Impacts of Poor Sanitation in Africa: Zambia. Water and Sanitation Program, Washington, DC.

WSP (2016) Africa FY15 Highlights and Achievements. Water and Sanitation Program, Washington, DC. 
WUTICH A (2009) Intrahousehold disparities in women and men's experiences of water insecurity and emotional distress in urban Bolivia. Med. Anthropol. Q. 23 436-454. https://doi. org/10.1111/j.1548-1387.2009.01072.x

WUTICH A and BREWIS A (2014) Food, water, and scarcity: toward a broader anthropology of resource insecurity. Curr. Anthropol. 55 444-468. https://doi.org/10.1086/677311

WUTICH A and RAGSDALE K (2008) Water insecurity and emotional distress: Coping with supply, access, and seasonal variability of water in a Bolivian squatter settlement. Soc. Sci. Med. $672116-$ 2125. https://doi.org/10.1016/j.socscimed.2008.09.042

XIONG YJ, HAO XR, LIAO C and ZENG ZN (2016) Relationship between water-conservation behavior and water education in Guangzhou, China. Environ. Earth Sci. 75 1-16. https://doi. org/10.1007/s12665-015-4873-x 